\title{
REPRESENTAÇÕES DO ALUNO DE GRADUAÇÃO EM ENFERMAGEM ACERCA DA PRÁTICA/PAPEL DO ENFERMEIRO - UM RELATO DE EXPERIÊNCIA *
}

\author{
Maria Geralda G. Aguiar** \\ Rita Narriman Silva de O. Boery***
}

\begin{abstract}
RESUMO: As autoras relatam uma experiência vivenciada pelos alunos da disciplina Introdução à Enfermagem, ao utilizarem música, dramatização, telejomal e cartazes, como forma de expressão de sua visão da profissão. Através dessa atividade prática comemorativa do Dia do Enfermeiro, buscaram conhecer as representações do aluno acerca da prática e do papel do enfermeiro. Tal atividade possibilitou a reelaboração de conceitos teóriocos já abordados em sala de aula; constituiu-se como espaço de reflexão dos elementos sugeridos pelas imagens apresentadas na produção dos grupos. As múltiplas dimensőes da prática profissional, enfocadas nas representaçőes dos alunos, forneceu subsídios para repensar as estratégias do processo ensinoaprendizagem nesta disciplina.
\end{abstract}

ABSTRACT: The authors report a practical experience which took place with the students of the discipline Introduction to Nursing, about the use of music, drama, TV news and bills to express their Nursing Conceptions. Through a commemorative practical activity of Nurses' Day, the authors tried to know student's representations concerning the practice and role of the nurse. Such an activity enabled us to reelaborate theoretical concepts worked in the classroom and constituted itself a space to think about the data suggested by the images produced by the sudents team. The multiple dimension of professional practice focused in sudents representations, provived ground to rethink the strategies of the teachig - leaming process in the discipline.

UNITERMOS: Enfermagem - Prática - Papel do Enfermeiro.

\section{INTRODUÇÃO}

O tema enfermagem como profissão com enfoque nas tendências da prática profissional, corresponde à primeira unidade do programa da Disciplina Introdução à Enfermagem, integrante do currículo do curso de Enfermagem da Universidade Estadual do Sudoeste da Bahia.

Esse tema sempre é desenvolvido sob forma de exposição dialogada entre docentes e discentes, tendo uma duração de vinte horas.
Como docentes da disciplina em questão e preocupadas com a dinamização do processo ensinoaprendizagem, decidimos introduzir no primeiro semestre de 1993, como recurso didático, o estudo dirigido e verificamos que as discussões em sala de aula, foram énriquecidas, ou seja, tornaram-se mais abrangentes.

Dado o grande número de alunos (quarenta e quatro), até então a maior turma da disciplina, aliada à capacidade de produção demonstrada pelo grupo, fomos motivadas a realizar um atividade extra curri-

Trabalho apresentado como tema livre no $45^{\circ}$ Congresso Brasileiro de Enfermagem. Olinda-Recife-PE, 28 de novembro a 3 de dezembro de 1993.

* Professora Assistente da Universidade Estadual do Sudoeste da Bahia - Departamento de Saúde - Campus de Jequié. Aluna do Programa de Pós-Graduação nivel de Mestrado da Escola de Enfermagem - USP, área de concentração em Enf ermagem Psiquiátrica.

'** Prof essora Assistente da Universidade Estadual do Sudoeste da Bahia - Departamento de Saúde - Campus de Jequié. Especialista em Enfermagem Médico-Cirúrgica. 
cular, que coincidiu com a comemoração do Dia do Enfermeiro.

Com tal atividade, além do aspecto comemorativo, poder-se-ia conhecer a percepção do aluno, de uma forma dinâmica e atraente, sobre a enfermagem como profissão; realizar atividade em conjunto, visando integrar os grupos de estágio; estimular a criatividade do aluno através de recursos altemativos, pouco habituais em sala de aula (Música, Dramatização, Telejomal e cartazes) como forma de expressão da sua visão da profissão e do profissional enfermeiro.

\section{PLANEJAMENTO E EXECUÇÃo DA ATIVIDADE PROPRIAMENTE DITA}

Inicialmente, realizou-se uma reunião preparatória entre as professoras da Disciplina, para discutir a estratégia a ser utilizada na comemoração do Dia do Enfermeiro.

Decidiu-se então: conservar a mesma divisão dos grupos, feita para a realização dos estágios requeridos pela disciplina, já que seria também uma oportunidade de integração entre os alunos; dar uma orientação inicial para a realização da atividade; interferir o mínimo possível durante o planejamento e execução da atividade pelos alunos, visando com isso explorar sua livre expressão e criatividade; utilizar a Música, a Dramatização, o Telejomal e o Cartaz, como meio para representar a imagem que têm da profissão.

: Nesse sentido, foram providenciados os recursos materiais básicos e os encaminhamentos burocráticos relativos à reserva do auditório, filmagem, fotografia, etc.

No dia 12.05 , no início da manhã, o grupo reunido em sala de auia, tomou conhecimento da idéia de comemorar juntos, professores e alunos, o Dia do Enfermeiro e a forma como seria feito isso. A receptividade foi positiva e logo foram feitas as orientações e o sorteio dos recursos didáticos para cada grupo.

A partir daí, cada um ocupou uma sala diferente, de forma que um grupo não teve conhecimento da produção do outro, a fim de evitar interferências nos modos de percepção da profissão.

Trabalharam então, durante uma hora, sendo assessorados por duas professoras da disciplina, que proviam os recursos materiais necessários e acompanhavam a execução da atividade.

O trabalho foi desenvolvido conf orme planejado, embora tenham surgido alguns entraves administrativos que atrasaram e quase inviabilizaram tais ativida- des. Isso provocou um desgaste pessoal das professoras, natentativa de solucionar as dificuldades, deixando-as apreensivas quanto a possíveis prejuizos na dinâmica do trabalho como um todo.

A apresentação dos grupos foi ordenada previamente, onde cada um dispôs de vinte munidos para apresentar-se.

\section{A APRESENTAÇÃO PÚBLICA E ANÁLISE DA PRODUÇÃO DOS GRUPOS}

O primeiro grupo a apresentar-se fez uma dramatização, enfocando, inicialmente, a admissão de uma paciente num pronto socorro.

Enfatizou o contexto de trabalho da enfermagem mostrando que as atividades da enfermagem não são isoladas, mas sim trabalho que se constrói coletivamente.

A equipe de saúde representada no palco, compunha-se de todas as categorias de enfermagem, de médicos e incluía o aluno, como estagiário. Percebeuse a valorização do trabalho em equipe, enquanto um processo integrado.

No entanto, observou-se diferenças na forma como cada um exercia o seu papel de profissional.

A representação da enf ermeira expressava-se nos estereótipos de uma imagem negativa - enfermeira distante do paciente, insensível à atuação vivida por ele, utilizando-se de gestos bruscos e atitude desanimadora; e por outro lado, uma imagem positiva enfermeira dócil, dedicada, demonstrando tranquilidade no exercício da profissão.

$O$ auxiliar de enfermagem apareceu mais próximo de paciente e do familiar, sost que preocupavase em atendê-los, fazendo o elo de ligação com a família. Percebeu-se ainda, a enfermagem num papel de defesa do paciente, diante do restante da equipe.

Visualizou-se também a aflição do familiar diante de uma atendente de enfermagem fria, impessoal, preocupada em cumprir as normas institucionais preenchimento de fichas, coleta de dados do paciente - alheia a dor do familiar.

Assim, o gnupo critica a realidade de saúde do país e diz que partiu daquilo que imagina ser o trabalho da enfermeira.

Cada um procurou passar um pouco da visão que tem da enfermagem, embora reconheçam que não têm experiência, já que ainda não vivenciaram na prática, situações assistenciais. 
O segundo grupo trabalhou com cartazes. Houve uma preocupação dos alunos em introduzir os cartazes com um texto oral, onde buscaram fundamentar teoricamente sua concepção de enfermagem.

Usaram, para tal, um trecho do Manual de Enfermagem, de Thora Kron, onde é abordada a enfermagem como profissão numa perspectiva histórica, sua evolução, mostrando um lado de submissão presente no enfermeiro e concluindo que a Enfermagem nunca vai ser Medicina.

A visão que têm da enfermagem, num primeiro momento, sugere-nos a concepção da profissão como Ciência e Arte. Utilizam-se de escritos de Florence Nightingale para conceituá-la.

Num segundo momento, colocam a enfermagem numa perspectiva ecológica, de totalidade, ou seja, holística. Nesta concepção, a enfermeira atende ao homem, enquanto ser social, no âmbito intra e extra institucional. Assim, o individual e o coletivo, não são categorias separadas ou dicotômicas. Na visão holística, a enfermagem aparece como fonte de vida, como força produtora de saúde, mas é um trabalho duro, tendo em vista o contexto onde ela se produz e reproduz - a divisão do trabalho, no campo de saúde e de enfermagem, o poder médico e o saber da enfermagem.

O primeiro cartaz do grupo, dizia: Lembrem, remédios podem matar. Esta frase acompanhada da imagem de um revólver que dispara cápsulas, é sugestiva do poder das drogas - terapêutico e no vivo. A cor azul, presente em todas as cápsulas representa o lado positivo (terapêutico) das drogas. O outro lado da cápsula, representado por três tonalidades diferentes de amarelo, sugere a intensidade de toxidade delas. Pareceu-nos o texto de uma campanha educativa dirigida à população ou quem sabe aos próprios enfermeiros? O cartaz é, sem dúvidas, um lembrete para o enfermeiro de que ele tem um papel decisivo na Educação em Saúde. É também um alerta sobre o grave problema de Saúde Pública, representado pelo uso indiscriminado de drogas.

Nesse sentido é papel do enfermeiro ensinar pessoas a usar remédios de maneira sensata e limitada.

O segundo cartaz mostrou uma população em franco crescimento. $\dot{E}$ preciso oferecer condiçðes de vida ideais a todo esse contingente humano, e saúde é algo que tem a ver com as condições de vida reais da população. Enfocou, ainda, o homem como um todo, mostrando a questão do humano - humanidade. A figura da colagem, representa homens, mulheres e crianças, em várias etapas do ciclo vital, evidenciando que para a assistência do enfermeiro não existe faixa de idade determinada. E ainda, que o objeto da enfermagem é o homem, tanto individual quanto coletivamente.

É dever do Estado e função do enfermeiro, enquanto cidadão e profissional de saúde, trabalhar com/e para o indivíduo, de forma que ele perceba que saúde não é algo desvinculado de suas condições de vida e existência.

O terceiro e último cartaz, engloba mensagens distintas, das quais destacamos os seguintes aspectos: a enfermagem aparece dando duro, acompanhando o curso da vida. A frase como aproveitar melhor os dons da natureza, sugere o papel educativo do enfermeiro; reforça a esperança de quem vivencia uma situação de dor. Partindo dessa perspectiva $a$ enfermagem faz muita coisa para melhorar a vida do outro.

A valorização que o aluno atribui à profissão - ela é especial, daí o pedido que seja reconhecida.

A profissão precisa de reconhecimento social. Consideram que o enfermeiro é um trabalhador de saúde necessário em toda cidade, reforçada por outra frase. Toda cidade precisa de um trabalhador como este. A responsabilidade do enfermeiro ao assistir o paciente/cliente, por exemplo, na manipulação de equipamentos e materiais.

A enfermagem contribui em diversos campos de atuação, seja nas situações de emergências, levando um fio de esperança ao dar os primeiros socorros primeiro atendimento - ou nas situações cotidianas no âmbito das enfermarias, ambulatórios ou salas cirúrgicas.

Situam a Escola de Enfermagem fazendo uma homenagem e uma alusão aos dez anos do Cursos de Enfermagem dessa Universidade.

A frase introduzimos, desenvolvemos e lideramos ressalta que o curso foi introduzido pela escola, na região do Sudoeste da Bahia, desenvolveu-se e vem liderando nesses dez anos. Por isso está de parabéns.

O grupo se inclui no contexto local e geral da enfermagem, quando se coloca como uma nova força, lembrando ao órgão formador - universidade - 0 compromisso com a geração do futuro.

Escolha o seu amanha foi a forma que encontraram para dizer que puderam e podem, no Curso de Enf ermagem, escolher o tipo de profissional que se- 
rão amanhã, apresentando elementos de sua concepção da enfermagem e do enfermeiro na constituição do conceito elaborado.

Dessa forma, o grupo buscou unir uma concepção teórica da enfermagem como profissão, utilizando autores como Kron, Nightingale. A sua perspectiva parte do concreto vivido em sala de aula, da visão do senso comum, das imagens da profissão veiculadas pelos teóricos, pelos meios de comunicação de massa e pelos professores.

Também este gnupo valoriza a união da equipe de saúde, nunca representando o enfermeiro numa situação de trabalho isolada.

O terceiro grupo, trabalhou sob a forma de um telejomal. Na introdução à reportagem foi apresentado o conceito da enfermagem enquanto processo que envolve uma relação de troca entre os trabalhadores em saúde e o paciente/cliente.

A Câmara, denominada teleenferma, focalizou a repórter que noticia as comemoraçð̃es do Dia do Enfermeira. Depois da introdução ao tema, entram na reportagem propriamente dita, indo à rua, entrevistar pessoas que dão a sua visão sobre a enfermagem (visão do outro); e indo ao hospital onde entrevistam enferıneiras que falam de sua visão sobre si mesmas.

Utilizam como personagens as enfermeiras Malvina Malvada e Angélica Angelical, representantes de papéis opostos, para mostrar a sua visão sobre a enfermagem. Personagem estereotipada do papel profissional da enf ermeira, Malvina Malvada é burocrata, preocupada com normas e rotinas e declara que na verdade gostaria de ser médica.

Seu desejo não realizado, além do desprestígio social da profissão, é um peso muito grande para ela e a deixa desmotivada no trabalho. Assim, Malvina Malvada justifica seu discurso: reconhece que o auxiliar de enfermagem lida com o pesado no trabalho e diz que cuida dor pacientes porque não tem outro jeito, pois só cabe, à enfermeira, a supervisãc.

Já Angélica Angelical, adora a profissão, sempre quis ser enfermeira, encontra respostas para as suas necessidades profissionais no trabalho, é um anjo bom.

Num primeiro momento, a visão de senso comum sobre a enfermagem e o enfermeiro, é através da entrevista de pessoas, numa cena de rua. Tentam discutir os porquês da visão distorcida de socieda ${ }^{2} e$ sobre a enfermagem e os enfermeiros. Colocam-se no papel de transeuntes para abordar a visão do senso comum sobre a profissão e os profissionais.
O gnupo coloca em questão, através dos discursos de Malvina Malvada e AngélicaAngelical, o que é ser enfermeira. De forma estereotipada, cada personagem traz elementos negativos ou só positivos em seu papel; tanto o descompromisso da prática de Malvina Malvada (imagem de enfermeira má), como a satisfação de Angélica Angelical só em ver o paciente recuperado (a imagem de anjo bom e abnegado, que tudo faz por amor ao trabalho), objetivam-nas em papeis cristalizados. Esses papéis, portanto, devem ser mobilizados, transformados.

O gnupo coloca em questão o papel e a prática da profissão, que no discurso de Malvina Malvada aparece como prática descontextualizada, a-crítica, ahistórica. Seu papel é passivo, de mera cumpridora de tarefas - não se coloca no que faz. Angélica Angelical gosta da profissão, acha que a escolheu acertadamente, pensa sua prática no contexto do trabalho em saúde como um todo. Chega a abordar a problemática dos baixos salários, mas como algo que pode ser sublimado diante da satisfação profissional em ver o paciente recuperado. $\mathrm{O}$ gnupo se utiliza dessas personagens para a bordar a importância da motivação pessoal na escolha da profissão. Revela também, a sua inquietação com o futuro profissional.

O quarto e o último grupo, mostrou a sua visão, através da música. Lançou mão de um arranjo de uma música de Roberto Carlos, que serviu de base a letra de autoria de um componente do grupo, para homenagear a enfermeira. Como se segue:

\section{"Elegante sempre está \\ Neve perde com sua cor \\ Faz de tudo para salvar \\ Ela é mesmo um resplendor!}

\section{Enfermeira, enfermeiro}

Sempre dando seu amor

Faz de tudo para salvar

Ela é mesmo um resplendor. $A i, A i, A i$.

Rr-vincias semp-e faz

Miergulhando no seu intimo

E. também no seu espirito

E'eva o seu astral! $A i, A i, A i$.

\section{Inteligente e competente \\ Determinada deve ser \\ Na luta com o doente \\ Vai até o amanhecer".}

Percebe-se na música, que doiada dos atributos de uma musa, vai se compondo o perfil da enf $t$ ' meira, mulher merecedora de homenagens, por seu penoso ofício de lidar com a dor e a morte. 
A letra, composta por um dos componentes do grupo, inicia com uma descrição de traços exteriores da enfermeira, dizendo ser ela elegante. Passa para a forma como exerce a prática - trabalha por amor e é capaz de renúncias. $\mathrm{O}$ amor e a renúncia elevam o seu astral. Compżem em seguida, a personalidade da enfermeira. Ela é inteligente, determinada. A qualidade de seu trabalho vem da competência no cuidado do doente. Observa-se que à imagem inicial da enfermeira abnegada, dócil, vão se juntando a rributos que sugerem força e exercício ativo do papel profissional. Em outras palavras, "ela sai de uma posição passiva para uma posição ativa no contexto do cuidado em Saúde"(1). Assim, os alunos idealizam o papel da enfermeira na assistência direta ao paciente, buscando-o na sua formação, pois eles assistem para aprender a administrar a assistência.

Por outro lado, é exigida a competência no trabalho, assim como a devoção - a enfermeira luta, $f a z$ tudo para salvar o doente. Traz a idéia de onipotência da enfermeira, adquirido certamente, na formação profissional. A Enfermeira luta com o doente - nesta frase a concepção de prática técnico-humanitária da enfermeira representada pelo gnupo, é superada em certa medida pelo encarar da doença, enquanto experiência de sof rimento, junto com o paciente.

Diante disso percebe-se que a prática da enfermeira, não é tecnicamente neutra, mas trabalho cujo objeto é o humano, volta-se para o corpo social do paciente.

Nota-se ainda o caráter ambíguo da enfermeira representada na música. Ela sabe qual é o seu papel, pois tem competência e determinação, mas é movida por amor e renúncia. $O$ estereótipo de anjo bom que tradicionalmente acompanha a enfermeira - a devoção, renúncia e abnegação, - negam a sua condição humana. Assim o seu ser é negligenciado, pois ela deve deixar de sentir e de sof rer; e se sof re ao enfrentar cotidianamente situações de dor e morte, deve sublimar.

A esse respeito vale ressaltar o estudo de MENZIES (3), sobre os mecanismos de defesa socialmente construídos pelas enfermeiras, ao lidar com situaçð̃es estressantes, relativas ao seu próprio objeto de trabalho.

Para o gnupo, a enfermeira luta, enf renta a dor, a doença, a morte, para salvar o doente. Assim se evidencia a onipotência que a enfermeira carrega consigo desde a sua formação.

Durante a apresentação, o pequeno público com- posto pela turma e alguns professores de outras disciplinas, canta e dança no rítmo da timbalada.

De algum modo ele esboça um movimento de contestação, quando a música romântica, suave, é transposta para um rítmo mais moderno, onde cada um se solta e se move de acordo com sua própria cadência. Simbolicamente, temos a enfermagem do dois prá lá, dois prá cá da música romântica, mas a enfermeira é o sujeito que articula, na prática concreta, os atributos do ser enfermeiro com sua cadência própria - com seu rítmo e jeito pessoal, individualizado. Fato este negligenciado durante sua formação (2).

Falando de outra forma, a formação acadêmica é apenas referência teórico-prática, na qual se fundamenta o exercício ativo da profissionalidade da enfermeira, e não referência que molda seu papel profissional.

Assim, do modo suave e delicado de se dançar uma música romântica, passamos à timbalada, colocando a enfermeira homenageada no contexto da Bahia. A dança dos alunos nos sugere a imagem de uma enfermeira que se move, trabalha e cria, além daquilo que está instituído - o papel institucionalizado.

\section{ALGUMAS CONSIDERAÇÕES FINAIS}

Após as apresentaçð̃es, foi possível discutir-se reflexivamente sobre alguns elementos sugeridos pelas imagens colocadas em cena - do drama de trabalhar num Pronto Socorro de um hospital sem recursos; nas informaçð̃es veiculadas pela televisão, enquanto meio de comunicação de massa - telejornal (Teleenferma); no quadro composto pelas colagens, onde figuras e texto, fundem-se numa representação que marca, situa, define o espaço de atuação e a prática profissional; na música que não possibilita contestação de atributos tradicionais, historicamente, associados à imagem da enfermeira sobre si mesma e por outros.

Na nossa perspectiva, enquanto docentes da disciplina, a atividade possibilitou a expressão de conceitos teóricos abordados em sala de aula, de modo crítico e ao mesmo tempo criativo, em que o sentido lúdico do aprender criando, esteve sempre presente.

Além de contemplar as expectativas do aluno, foi uma oportunidade de obter subsídios para repensar as aulas da $\mathrm{I}^{\mathrm{a}}$ unidade, o desempenho das professoras $\mathrm{e}$ as estratégias utilizadas.

Os trabalhos continham, essencialmente, mensa- 
gens sobre a profissão e o papel do enfermeiro nas suas diversas dimensões.

A discussão das concepç̃es da enfermagem, da enfermeira, da saúde, do paciente e do trabalho em saúde, objetiva ou subjetivamente sugeridas pelas cenas dramatizadas, pelo telejornal, pela música cantada e dançada, e pela composição formada pelas colagens, aparecem como momento de reflexão, de tomada de consciência pelo grupo, da complexidade que envolve o exercício ativo da profissão. Nessa perspectiva, a reflexão crítica deve levar a um posi- cionamento da enfermagem, visando a transformação das atuais condiçð̃es de trabalho no campo da saúde. Para que isso ocorra torna-se necessário que o profissional exerça mais do que um simples papel-função, mas busque 0 aperfeiçoamento de seus conhecimentos. A competência técnico-científica é condição necessária para a valorização da profissão. Além disso, o profissional deve questionar-se sobre o seu verdadeiro papel. Só o posicionamento político do enfermeiro lhe possibilitará uma nova conduta, uma nova prática.

\section{REFERÊNCIAS BIBLIOGRÁFICAS}

1. AGUIAR, M.G.G. $O$ trabalho cotidiano da enfermeira num hospital psiquiátrico em transformaçào - Uma análise a partir de representações sociais e da prática. São Paulo, 1991, 32p. (Projeto de Dissertacão Mestrado). Escola de Enfermagem, Universidade de São Paulo, 1991.

2. DOSATII, M.S., BOERY R.N.S. e LASELVA, C.R. Enfermeiro educador: Objeto de decor-ação? São Paulo, 1990, 48p. (Trabalho final da disciplina investigação e análise de problemas da enf ermagem médico-cinúrgica, Escola Paulista de Medicina).
3. MENZIES, I.E.P. El funcionamento de los sistemas sociales como defensa contra la ansiedade - Informe de un estudo del servicio de enfermeras de um hospital general. In: MENZIES, I.E.P., JACQUES, E. Los sistemas sociales como defensa contra la ansiedad. Buenos Aires: Paidós, 1974, p.53-127.

Recebido para publicação em 30.9.93 